\title{
Arachnoid cysts: spontaneous resolution distinct from traumatic rupture
}

\author{
Case report
}

\author{
Ruth E. Bristol, M.D., Felipe C. Albuquerque, M.D., Cameron McDougall, M.D., \\ AND ROBERT F. SPETZLER, M.D.
}

Division of Neurological Surgery, Barrow Neurological Institute, St. Joseph's Hospital and Medical Center, Phoenix, Arizona

\begin{abstract}
$\checkmark$ Although many arachnoid cysts are discovered incidentally and require no intervention, a small subset has been known to rupture. Note that rupture can occur either spontaneously or in association with trauma. Based on a review of the literature on ruptured arachnoid cysts, it appears that patients with middle fossa cysts are more likely to experience symptomatic traumatic rupture than those with cysts in other locations. Middle fossa cysts are more commonly associated with hemispheric subdural collections and hematomas than are any other cysts. The authors report on two representative cases illustrating the distinct presentation, imaging characteristics, and management of these cysts.
\end{abstract}

\section{KEY WORDS • arachnoid cyst • asymptomatic arachnoid cyst • head injury • craniopharyngioma $\bullet$ spontaneous resolution}

$\mathrm{M}$ ANY ARACHNOID CYSTS are discovered incidentally in patients with minor head trauma, headache, or symptoms from another lesion. Symptoms can develop as cysts grow and exert mass effect on surrounding structures. However, many cysts remain asymptomatic, and thus their treatment remains controversial. ${ }^{16}$ In patients who do not receive treatment, spontaneous resolution has been reported with and without trauma. ${ }^{1,12}$ Minor trauma can be associated with asymptomatic resolution of a cyst, but moderate head trauma can result in subdural effusions with intracranial hypertension. Cysts in the middle fossa, cerebral convexity, and suprasellar, supracerebellar, and prepontine regions have been reported to resolve spontaneously and asymptomatically. ${ }^{5}$ In contrast, patients with traumatic symptomatic rupture are more likely to have middle fossa cysts.

\section{Illustrative Cases}

\section{Case 1}

History and Examination. This 5-year-old boy experienced minor head trauma with no loss of consciousness. A CT scan showed grossly enlarged suprasellar, prepontine, and basal cisterns. An initial MR imaging study revealed a large cystic structure that displaced the midbrain and pons superiorly and posteriorly. Contrast enhancement in

Abbreviations used in this paper: $\mathrm{CT}=$ computed tomography; $\mathrm{MR}=$ magnetic resonance. the suprasellar cistern was minimal (Fig. 1 left). The patient was asymptomatic, and routine follow up was recommended.

An MR image obtained 1 month later showed that the cystic structure had resolved completely and that the brainstem structures had resumed their normal position (Fig. 1 right). The parents denied the occurrence of any new trauma. Because the region of enhancement had enlarged, exploration for a presumed craniopharyngioma was recommended. This procedure was delayed for insurance reasons.

Operation and Postoperative Course. When the patient was examined again 1 year later, the cystic structure had returned and appeared larger than before. On surgery, multiloculated arachnoid cysts were found surrounding lesions containing cholesterol granules and regions of solid tumor. Enhancing tissue was consistent with craniopharyngioma. A gross-total resection was performed, and the patient tolerated the procedure well.

\section{Case 2}

History and Examination. This 17-year-old boy sought treatment for headache 3 days after a helmet-to-helmet collision on the football field. He suffered a brief loss of consciousness followed by tunnel vision and right eye pain. A CT scan showed a fluid collection in the right hemisphere contiguous with an arachnoid cyst of the middle fossa (Fig. 2). The patient's headache was well controlled with pain medication, but he experienced several 


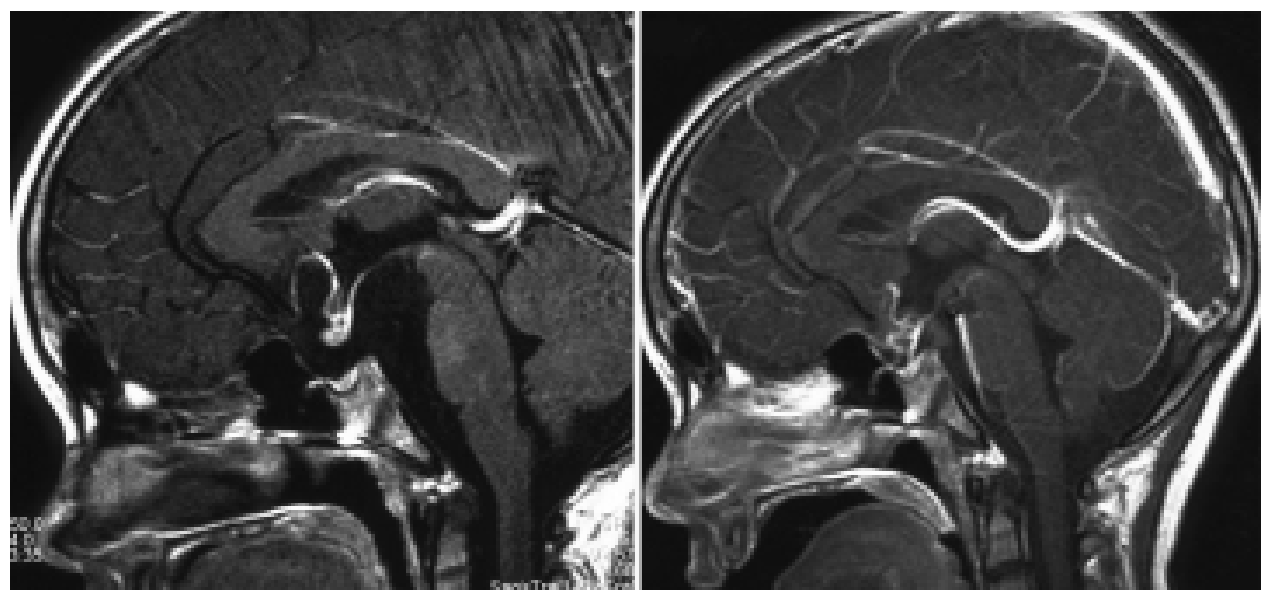

FIG. 1. Case 1. Left: Sagittal MR image obtained on presentation, showing a prepontine and suprasellar arachnoid cyst displacing the brainstem posteriorly. Right: Sagittal MR image obtained 1 month after presentation, revealing the disappearance of the arachnoid cyst during the intervening period and normal positioning of the brainstem structures.

episodes of bradycardia during observation. Even though he was asymptomatic during these episodes, the decision was made to evacuate the fluid and fenestrate the cyst.

Operation and Postoperative Course. On surgery, a small craniotomy was made over the sylvian fissure. When the dura mater was opened, clear fluid under high pressure was obtained. The cyst wall was fenestrated widely. No drain was placed. The patient had an uneventful postoperative course. Persistent bradycardic episodes were attributed to cardiovascular fitness in a young athlete.

\section{Discussion}

Arachnoid cysts compose approximately $1 \%$ of intracranial mass lesions,,${ }^{4,16,18}$ and their spontaneous rupture or resolution is rare. Prior reports of their disappearance have been associated with subdural hematomas, effusions, or meningitis. ${ }^{12}$ Other suprasellar cystic lesions, such as Rathke cleft cysts, dermoids, epidermoids, and cystic craniopharyngiomas, have also been associated with spontaneous rupture. Note that rupture of these lesions has resulted in meningitis and vasospasm. ${ }^{14,20}$ Arachnoid cysts have also been associated with other intracranial tumors, as in the patient in Case 1.7,8

The cause of spontaneous rupture is unknown. Trauma may cause the arachnoid layer to tear. The location of a tear would determine the site of communication: adjacent cisterns, ventricles, or subdural spaces. Even in patients with no known trauma, excessive breathing, coughing, or sport activities can produce sufficient force to tear the arachnoid. Alternatively, a change in the one-way valve that created the cyst may cause cerebrospinal fluid to egress. ${ }^{5}$ In patients with tumor-associated cysts, growth of the tumor or secretion of growth factors can have a mechanical or chemical effect on the arachnoid, causing it to rupture. As a result of their high levels of activity, children may be more prone to spontaneous lesion rupture than adults. Arachnoid cysts are most common in children. ${ }^{8}$ Resolution of both symptomatic and asymptomatic cysts over time may explain the decline in their number with age. ${ }^{22}$

A subset of patients with cysts who have experienced moderate head trauma appears to be prone to the development of subdural collections, as in the patient in Case 2. Although cerebrospinal hygromas are more common, an
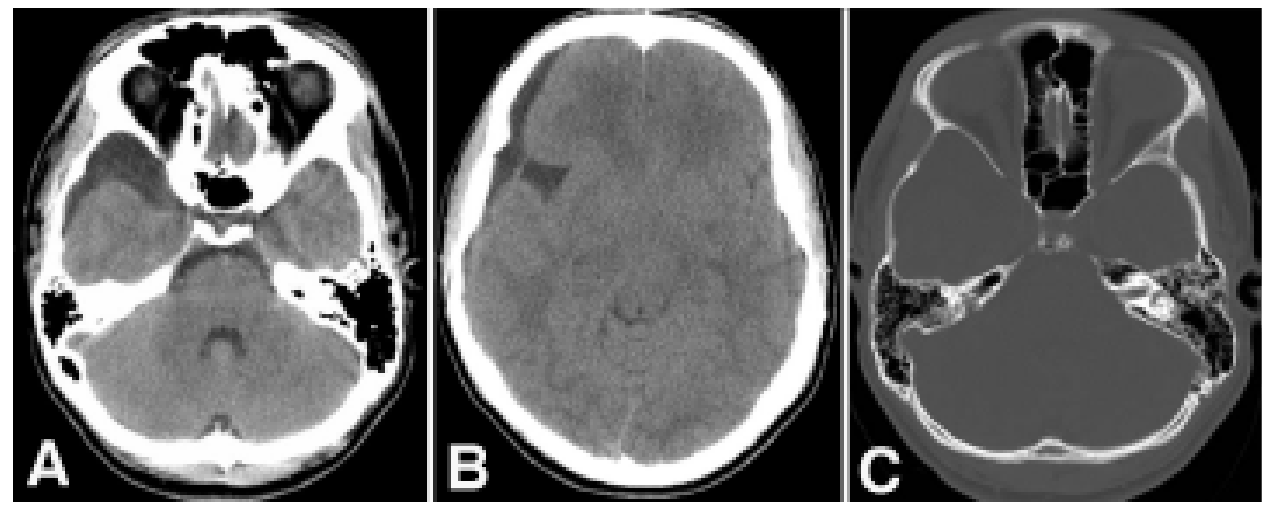

FIG. 2. Case 2. A and B: Axial CT soft tissue window scans demonstrating an arachnoid cyst involving the right middle fossa and contiguous extraaxial fluid collection. C: Axial CT bone window scan revealing right middle fossa remodeling associated with the longstanding arachnoid cyst. 
TABLE 1

Literature summary of patients wth spontaneous resolution of arachnoid cysts*

\begin{tabular}{llclr}
\hline \multicolumn{1}{c}{ Authors \& Year } & \multicolumn{1}{c}{ Cyst Location } & Age (yrs) & \multicolumn{1}{c}{ Presentation } & Time to Resolution (mos) \\
\hline Beltramello \& Mazza, 1985 & MF & 14 & headache, seizure & 7 \\
Inoue et al., 1987 & MF & 7 & diplopia & 18 \\
Weber et al., 1991 & temporal region & 3 & temporal bulging & 120 \\
Rakier \& Feinsod, 1995 & MF & 8 & headace, rt temporal bulging & 60 \\
McDonald \& Rutka, 1997 & MF & 2 & macrocephaly & 12 \\
Yoshioka et al., 1998 & MF & 0.17 & meningitis & 0.3 \\
Pandey et al., 2001 & supracerebellar region & 0.5 & macrocephaly, upgaze palsy & UK \\
Dodd et al., 2002 & prepontine region & 0 & none†s & 24 \\
Cokluk et al., 2003 & sylvian fissure & 10 & headache & 24 \\
& cerebral convexity & 1 & microcephaly & 18 \\
Poirrier et al., 2004 & MF \& occipital region & 15 & headache, vomiting & 132 \\
Moon et al., 2007 & suprasellar region & 5 & visual loss, incontinence & 120 \\
\hline
\end{tabular}

* No intervention was undertaken in any case except that reported by Poirrier et al., 2004; in that case, a drain/shunt was placed. Abbreviations: $\mathrm{MF}=$ middle fossa; $\mathrm{UK}=$ unknown.

$\dagger$ Cyst found on prenatal ultrasonography.

association between middle fossa cysts and subdural hematomas has been reported. ${ }^{2}$ These cases must be differentiated from traumatic subdural hematomas in patients with unruptured, incidental arachnoid cysts. ${ }^{9}$

A review of data reported in the literature supports our hypothesis that middle fossa cysts are more likely to result in symptomatic rupture, whereas those rupturing in other locations tend to be asymptomatic (Tables 1 and 2). We hypothesize that more arachnoid is exposed to potential tearing motions along the lateral dural surface in middle fossa lesions than that exposed in cysts associated with deep cerebral cisterns. Patients with acute subdural hematomas as a result of a ruptured cyst are also prone to elevated intracranial pressure and the need for surgical decompression. In the reported patients, intractable headache and neurological decline were seen only in those with traumatic rupture and subdural collections. The patient in Case 2 was essentially asymptomatic; however, the subdural fluid collection was similar in appearance to that in patients with intracranial hypertension. ${ }^{1}$ In a young person with a fluid collection creating mass effect, we believe decompression is reasonable.

As Beltramello and Mazza ${ }^{3}$ suggested in 1985, the decision to pursue surgery in these patients cannot be based on CT findings alone. Because the natural history of arachnoid cysts is variable and their treatment is controversial, cases of spontaneous resolution suggest that conservative management may be appropriate for many lesions. Patients should be informed of the risks of rupture as well as being educated about the neurological signs that might warrant treatment. We believe that intervention should be reserved for symptomatic or progressive lesions.

\section{References}

1. Albuquerque FC, Giannotta SL: Arachnoid cyst rupture producing subdural hygroma and intracranial hypertension: case reports. Neurosurgery 41:951-956, 1997

2. Auer LM, Gallhofer B, Ladurner G, Sager WD, Heppner F, Lechner H: Diagnosis and treatment of middle fossa arachnoid cysts and subdural hematomas. J Neurosurg 54:366-369, 1981

3. Beltramello A, Mazza C: Spontaneous disappearance of a large middle fossa arachnoid cyst. Surg Neurol 24:181-183, 1985

4. Boop F, Teo C: Congenital intracranial cysts, in McLone D (ed): Pediatric Neurosurgery. Surgery of the Developing Nervous System, ed 4. Philadelphia: WB Saunders, 2001, pp 489-497

5. Cokluk C, Senel A, Celik F, Ergur H: Spontaneous disappearance of two asymptomatic arachnoid cysts in two different locations. Minim Invasive Neurosurg 46:110-112, 2003

6. Dodd RL, Barnes PD, Huhn SL: Spontaneous resolution of a prepontine arachnoid cyst. Case report and review of the literature. Pediatr Neurosurg 37:152-157, 2002

7. Doglietto F, Sabatino G, Pallini R: Clivus chordoma associated with a pontine arachnoid cyst. Lancet Oncol 6:536, 2005

TABLE 2

Literature summmary of patients with traumatic rupture of arachnoid cysts*

\begin{tabular}{clcllc}
\hline \hline Authors \& Year & Cyst Location & Age (yrs) & \multicolumn{1}{c}{ Trauma } & Symptom & Intervention \\
\hline Mori et al., 1995 & MF & 4 & MVA & lethargy, GCS score 9 & none \\
& MF & 0.75 & blunt trauma & UK & none \\
& MF & 13 & blunt trauma & UK & none \\
& frontal region & 29 & headache after diving & headache, vomiting & drain \\
& frontal region & 17 & blunt trauma & UK & drain \\
Albuquerque & MF & 6 & sports-related fall & headache, lethargy & drain/shunt \\
\& Giannotta, 1977 & MF & 25 & assault & lethargy & drain \\
& MF & 9 & blunt trauma & headache, lethargy & drain \\
& MF & 25 & blunt trauma & headache, lethargy & drain/shunt \\
& MF & 10 & none & headache, vomiting & shunt \\
\hline
\end{tabular}

* GCS = Glasgow Coma Scale; MVA = motor vehicle accident. 
8. Goda M, Tashima A, Isono M, Hori S, Kimba Y: A case of hypothalamic hamartoma associated with arachnoid cyst. Childs Nerv Syst 15:490-492, 1999

9. Inoue T, Matsushima T, Tashima S, Fukui M, Hasuo K: Spontaneous disappearance of a middle fossa arachnoid cyst associated with subdural hematoma. Surg Neurol 28:447-450, 1987

10. McDonald PJ, Rutka JT: Middle cranial fossa arachnoid cysts that come and go. Pediatr Neurosurg 26:48-52, 1997

11. Moon KS, Lee JK, Kim JH, Kim SH: Spontaneous disappearance of a suprasellar arachnoid cyst: case report and review of the literature. Childs Nerv Syst 23:99-104, 2007

12. Mori T, Fujimoto M, Sakae K, Sakakibara T, Shin H, Yamaki T, et al: Disappearance of arachnoid cysts after head injury. Neurosurgery 36:938-942, 1995

13. Pandey P, Tripathi M, Chandra PS, Singh VP, Mehta VS: Spontaneous decompression of a posterior fossa arachnoid cyst: a case report. Pediatr Neurosurg 35:162-163, 2001

14. Patrick BS, Smith RR, Bailey TO: Aseptic meningitis due to spontaneous rupture of craniopharyngioma cyst. Case report. J Neurosurg 41:387-390, 1974

15. Poirrier AL, Ngosso-Tetanye I, Mouchamps M, Misson JP: Spontaneous arachnoid cyst rupture in a previously asymptomatic child: a case report. Eur J Paediatr Neurol 8:247-251, 2004

16. Raffel C, McComb JG: To shunt or to fenestrate: which is the best surgical treatment for arachnoid cysts in pediatric patients? Neurosurgery 23:338-342, 1988

17. Rakier A, Feinsod M: Gradual resolution of an arachnoid cyst after spontaneous rupture into the subdural space. Case report. J Neurosurg 83:1085-1086, 1995
18. Rengachary SS, Kennedy JD: Intracranial arachnoid cysts and ependymal cysts, in Wilkins RH, Rengachary SS (eds): Neurosurgery, ed 2. New York: McGraw-Hill, 1996, Vol 3, pp 3709-3728

19. Romero FJ, Rovira M Jr, Ibarra B, Piqueras J, Rovira M: Arachnoid cysts with intracystic and subdural haematoma. Eur J Radiol 9:119-120, 1989

20. Shida N, Nakasato N, Mizoi K, Kanaki M, Yoshimoto T: Symptomatic vessel narrowing caused by spontaneous rupture of craniopharyngioma cyst - case report. Neurol Med Chir (Tokyo) 38:666-668, 1998

21. Weber R, Voit T, Lumenta C, Lenard HG: Spontaneous regression of a temporal arachnoid cyst. Childs Nerv Syst 7: 414-415, 1991

22. Yamakawa H, Ohkuma A, Hattori T, Niikawa S, Kobayashi H: Primary intracranial arachnoid cyst in the elderly: a survey on 39 cases. Acta Neurochir (Wien) 113:42-47, 1991

23. Yoshioka H, Kurisu K, Arita K, Eguchi K, Tominaga A, Mizoguchi N, et al: Spontaneous disappearance of a middle cranial fossa arachnoid cyst after suppurative meningitis. Surg Neurol 50:487-491, 1998

Manuscript submitted December 22, 2006.

Accepted January 11, 2007.

Address reprint requests to: Robert F. Spetzler, M.D., c/o Neuroscience Publications, Barrow Neurological Institute, 350 West Thomas Road, Phoenix, Arizona 85013. email: neuropub@ chw.edu. 